\title{
Constraints and triggers: Situational mechanics of gender in negotiation.
}

\section{Citation}

Bowles, Hannah Riley, Linda Babcock, Kathleen L. McGinn. 2005. Constraints and Triggers : Situational Mechanics of Gender in Negotiation. Journal of Personality and Social Psychology 89 (6): 951-965.

\section{Permanent link}

http://nrs.harvard.edu/urn-3:HUL.InstRepos:38036097

\section{Terms of Use}

This article was downloaded from Harvard University's DASH repository, and is made available under the terms and conditions applicable to Other Posted Material, as set forth at http:// nrs.harvard.edu/urn-3:HUL.InstRepos:dash.current.terms-of-use\#LAA

\section{Share Your Story}

The Harvard community has made this article openly available.

Please share how this access benefits you. Submit a story. 
Running head: GENDER IN NEGOTIATION

Constraints and Triggers: Situational Mechanics of Gender in Negotiation

Keywords: gender, negotiation, situation, ambiguity, representation 


\begin{abstract}
The authors propose two categories of situational moderators of gender in negotiation: situational ambiguity and gender triggers. Reducing the degree of situational ambiguity constrains the influence of gender on negotiation. Gender triggers prompt divergent behavioral responses as a function of gender. Field and lab studies ( 1 and 2 ) demonstrate that decreased ambiguity in the economic structure of a negotiation (structural ambiguity) reduces gender effects on negotiation performance. Study 3 shows representation role (negotiating for self or other) functions as a gender trigger by producing a greater effect on female than male negotiation performance. Study 4 shows decreased structural ambiguity constrains gender effects of representation role, suggesting situational ambiguity and gender triggers work in interaction to moderate gender effects on negotiation performance.
\end{abstract}


Constraints and Triggers: Situational mechanics of gender in negotiation The first major wave of research on gender in negotiation surged and subsided with trends in the psychological study of individual differences. In the 1970s and early 1980 s, there was an abundance of studies testing whether the sex of a negotiator would be a stable and reliable predictor of bargaining behavior and performance. Scholars who reviewed this literature reported an assortment of null and contradictory findings (Rubin $\&$ Brown, 1975; Thompson, 1990). By the early 1990s, most researchers in the field had discarded the gender variable with a heap of other individual differences that had failed over scores of tests to produce consistent results.

The contradictions from this first wave of research on gender in negotiation became the puzzles motivating a second generation of investigation. Consistent with contemporary theories of gender and social behavior (Deaux \& LaFrance, 1998; Deaux \& Major, 1987; Kray, Galinsky, \& Thompson, 2002; Maccoby, 1990), this next generation of researchers started with the premise that gender effects in negotiation would arise under certain circumstances and be absent—or even reversed — in others (Kray et al., 2002; Kray \& Thompson, in press; Kray, Thompson, \& Galinsky, 2001; Pruitt, Carnevale, Forcey, \& Van Slyck, 1986; Stuhlmacher \& Walters, 1999; Walters, Stuhlmacher, \& Meyer, 1998). Walters et al.'s (1998) meta-analysis, for instance, showed that sex differences (favoring women) in cooperative behavior were much larger in studies of explicit negotiations than in negotiation-related matrix games (e.g., Prisoner's Dilemma). In a second meta-analysis, Stuhlmacher and Walters (1999) found that women (as compared to men) reached less favorable negotiation outcomes but factors, such as the relative power between the negotiators, the mode of communication, and the 
integrative potential of the task, moderated that effect. Subsequent experimental research has demonstrated how the activation of sex stereotypes in the negotiation context may produce gender effects favoring male or female negotiators, depending on the content of the stereotype and how it is introduced (Kray et al., 2002; Kray et al., 2001).

The current paper contributes to this second generation of research by proposing two categories of situational moderators that help to organize our broader understanding of when gender matters in negotiation. The first is the degree of situational ambiguity, which facilitates or constrains the influence of gender in negotiation. The second category is what we call gender triggers, which prompt a gender-based divergence in the behavioral response. We show that situational ambiguity and gender triggers are not only distinct categories of moderators of gender effects in negotiation, but that they may work in interaction, such that decreased situational ambiguity constrains the potential for gender triggers to influence negotiation performance.

\section{Situational Moderators of Individual Differences}

The two categories of situational moderators that we propose, situational ambiguity and gender triggers, are motivated by psychological theory on the fundamental situational moderators of personality on behavior: Mischel's (1977) notion of strong vs. weak situations and Snyder and Ickes' (1985) concept of precipitating situations.

\section{Strong vs. Weak Situations}

According to Mischel (1977), psychological situations (i.e., stimuli, treatment) are "strong" to the extent that everyone has the same understanding of how they are supposed to respond and everyone has the will and ability to respond as expected. Strong situations are structured so that there is one clear and appropriate response, and, as a result, 
"individual differences become minimal and situational effects prepotent" (Mischel, 1977, p. 347). Weak situations are ambiguously structured so that people have to come up with their own interpretations as to what is the appropriate response, and the potential influence of individual differences, such as gender, is heightened.

There are a number of studies that show gender effects diminishing when experimenters reduce ambiguity within the psychological situation. For instance, Wood and Karten (1986) found that men in mixed-sex work groups were perceived to be more competent and engaged in more task behavior than women. However, when group members received test scores indicating task competence, measures of perceived competence and task behavior were correlated with test scores and unrelated to gender. Similarly, Dovidio and colleagues found that men in mixed-sex work pairs were more nonverbally dominant than women, but, when the experimenters manipulated the power asymmetry within the pair, nonverbal dominance was correlated with power and unrelated to gender (Dovidio, Ellyson, Keating, \& Heltman, 1988). Major and colleagues have shown that women have lower compensation expectations than do men (Bylsma \& Major, 1992; Major \& Konar, 1984; Major, McFarlin, \& Gagnon, 1984), but this gender gap in entitlement diminishes in the presence of clear wage comparison information (Major, McFarlin et al., 1984) or explicit performance feedback (Bylsma \& Major, 1992).

\section{Precipitating Situations}

Snyder and Ickes (1985) proposed a second, complementary category of situational moderator, which they called "precipitating situations." Whereas strong situations shift the cause of behavior from the individual difference to the situation, precipitating situations polarize behavioral responses as a function of the individual 
difference. Snyder and Ickes cited as an example of a precipitating situation Bem and Lenney's (1976) experiment in which they gave sex-typed individuals the choice of being photographed engaging in traditionally feminine or masculine behaviors (e.g., prepare a baby bottle or oil a squeaky hinge). This situation precipitated sex-type-based behavior by presenting participants with a forced choice which they would respond to differently depending on whether they identified with being masculine or feminine.

The activation of sex-stereotypes is another example of a precipitating situation. Sex-stereotypes cue men and women differently with regard to their comparative skills and abilities, and contribute through a dynamic of fulfilled expectations to sex differences in performance (Beyer, 1990; Beyer \& Bowden, 1997; Kray et al., 2002; Skrypnek \& Snyder, 1982; Steele, 1997; Zanna \& Pack, 1975). Gender roles similarly provide different information about what is the attractive or appropriate behavioral response to a situation depending on one's socially identified gender (Eagly, 1987; Eagly, Makhijani, \& Klonsky, 1992; Rudman \& Glick, 1999).

In sum, Mischel (1977) and Snyder and Ickes (1985) present two categories of situational characteristics that moderate the effects of individual differences on social behavior. One constrains the potential for individual differences to influence behavior, and the other triggers divergent behaviors as a function of the individual difference.

\section{Situational Ambiguity and Gender Triggers}

We adapt these concepts of strong vs. weak (Mischel, 1977) and precipitating situations (Snyder \& Ickes, 1985) to the study of gender in negotiation in terms of "situational ambiguity" and "gender triggers." 


\section{Situational Ambiguity}

We propose that the degree of ambiguity within a negotiation situation moderates the influence of individual differences, such as gender, on negotiation performance. We predict that the more ambiguity there is in the negotiation situation, the more potential there is for the individual difference to affect performance. There are multiple dimensions along which a negotiation situation could vary in ambiguity. For instance, the more ambiguity there is about how parties are supposed to interact with one another, the more potential there is for individual differences to influence negotiation behavior. Van Lange and Visser (1999) restructured a traditional implicit negotiation exercise (social dilemma) so that parties had the potential to change features of the negotiation context that would normally be fixed (viz., how interdependent their outcomes were). By introducing more potential for variation in how parties enacted the negotiation, the researchers were able to show that individual differences in social value orientation influence how interdependent parties make themselves depending on the cooperativeness of their counterparts' play.

Structural ambiguity. We propose that structural ambiguity is an important moderator of gender effects in negotiation. Structural ambiguity refers to the degree of uncertainty in parties' understanding of the economic structure of the negotiation. The economic structure is a centrally defining element of a negotiation situation and an important guide for negotiators' behavior (Lax \& Sebenius, 1986; Neale \& Bazerman, 1991; Raiffa, 1982; Thompson, 2005; Walton \& McKersie, 1965). It consists of the pool of resources available for distribution between the parties and the likely coordination points for agreement (Raiffa, 1982). Coordination points, such as "focal points" (e.g., a 50-50 split) and other standards for agreement (e.g., market values or social norms of 
fairness), help parties to agree on a specific settlement out of the potentially infinite set of possible outcomes (Schelling, 1980; White \& Neale, 1994).

The less parties understand about the limits of the bargaining range and appropriate standards for agreement, the more ambiguity there is in the negotiation situation. For instance, lack of information about one's own or the other party's negotiating limits creates uncertainty about what is attainable in the negotiation. Lack of clear standards for agreement (e.g., benchmarks or focal points), or the presence of multiple possible standards, creates uncertainty about the range of likely agreement. Increased structural ambiguity “weakens” the situation, in Mischel's (1977) terms, because it leaves parties with little guidance as to what is up for negotiation and how to judge what is a good or appropriate outcome. The weaker the situational stimulus, the more potential there is for individual differences, such as gender, to influence negotiators' performance. Decreased structural ambiguity, on the other hand, sharpens the situational stimulus, making the situational cues more dominant and reducing the potential influence of individual differences.

\section{Gender Triggers}

We use the term gender triggers to encapsulate those situational factors that, in Snyder and Ickes' (1985) terms, "precipitate" gender effects by prompting gender-related behavioral responses. There are many potential forms of gender triggers in negotiation. For instance, a recent meta-analysis by Stuhlmacher and Walters (1999) showed that the male advantage in negotiation is somewhat higher in single-issue negotiations, in which one party's gain is the other's loss, than it is in multi-issue negotiations with potential for mutual gain. This finding is consistent with gender role-based expectations that men 
would be more likely than women to engage in the types of highly competitive behaviors important to achieving good outcomes in single-issue negotiations (e.g., making aggressive first offers, refusing to yield) (Bakan, 1966; Eagly, 1987).

Another form of gender trigger that has been tested directly in negotiation contexts is the activation of sex-stereotypes (Kray et al., 2002; Kray et al., 2001). Kray and colleagues demonstrated that they could activate a form of stereotype threat (Steele, 1997) favoring men, by telling MBA students engaged in a competitive negotiation task that their performance would be highly diagnostic of their actual negotiation ability. Kray and colleagues then showed how explicitly activated stereotypes could elicit a form of stereotype reactance (Brehm, 1966) and produce counter-stereotypic negotiation results favoring women (Kray et al., 2001). Kray and colleagues later manipulated the content of sex stereotypes with regard to negotiation performance, and showed that participants' goal-setting and performance fulfilled the gendered expectations that the experimenters had created (Kray et al., 2002).

Representation Role. We propose that representation role (i.e., negotiating for oneself or someone else) is another potential gender trigger in negotiation. While there has been a fair amount of research and discussion in the negotiation field on the (dis)advantages of using a negotiating agent (Bazerman, Neale, Valley, \& Zajac, 1992; Croson \& Mnookin, 1997; Mnookin \& Susskind, 1999; Parks \& Conlon, 1995; Rubin \& Sander, 1988; Valley, White, Neale, \& Bazerman, 1992) and on the effects of constituent surveillance and accountability on negotiation behavior (Benton, 1972, 1975; Ben-Yoav \& Pruitt, 1984; Carnevale, Pruitt, \& Britton, 1979; Druckman, Solomon, \& Zechmeister, 1972; Frey \& Adams, 1972; Haccoun \& Klimoski, 1975; Pruitt et al., 1986; Wall, 1975; 
Wall \& Adams, 1974), we have uncovered no studies that test the effect of a simple role shift between negotiating for oneself vs. for someone else on gender differences in negotiation performance (cf. Druckman et al., 1972 on competing teams vs. individuals).

There are at least three streams of psychological theory and research that suggest that representation role could moderate the effect of gender on negotiation performance. One is the literature on entitlement, which shows that women (as compared to men) experience a relative lack of perceived deservedness for themselves that does not extend to similar others (Callahan-Levy \& Messe, 1979; Major, McFarlin et al., 1984). If women experience depressed deservedness with regard to themselves as compared to others, then shifting from promoting their own self-interest to advocating for others may lead them to have higher negotiation expectations (Major, Vanderslice, \& McFarlin, 1984).

Another explanation for why women may be more effective when negotiating on behalf of others than for themselves is that women (as compared to men) are more constrained by gender roles and stereotypes from advocating freely and effectively for themselves (Wade, 2001). Rudman and colleagues have demonstrated that women (as compared to men) who self-promote run a greater risk of social backlash (Rudman, 1998; Rudman \& Glick, 1999). Female negotiators may encounter more resistance from their counterparts when negotiating for themselves as opposed to someone else.

The literature on gender and self-construal suggests an alternative interpretation for why a shift in representation role would influence female negotiation behavior. Cross and Madson (1997) theorize that women tend to develop more interpersonally interdependent self-construals than do men. For individuals with interdependent selfconstruals, obligations to others and responsiveness to the needs of others motivate social 
behavior and shape social interactions. The core of implication of Cross and Madson's theory for gender and negotiation is that women may be especially motivated in negotiations in which they are responsible for representing the interests of another person as compared to situations in which they are representing only their own self-interest.

\section{Summary}

Motivated by theory on the situational factors that moderate the effects of individual differences on social behavior (Mischel, 1977; Snyder \& Ickes, 1985), we propose two categories of situational moderators of gender effects in negotiation: situational ambiguity and gender triggers. We propose that decreasing the degree of situational ambiguity "strengthens" the negotiation situation in Mischel's sense of the term, and thereby constrains the potential for gender to influence negotiation performance. Consistent with Snyder and Ickes' theory of precipitating situations, we propose that gender triggers cue the enactment of gender-relevant scripts and produce a gender-based divergence in response to the negotiation situation.

We propose that situational ambiguity and gender triggers are not only distinct forms of situational moderators of gender effects, but that they may work in interaction to moderate the influence of gender on negotiation performance. We theorize that strong situational cues compete with gender triggers for influence on negotiation performance. Reduced situational ambiguity constrains the influence of gender triggers by guiding behavior to follow non-gender specific scripts; increased situational ambiguity facilitates the influence of gender triggers by weakening the pull of non-gender specific scripts.

In Studies 1 and 2, we test one proposed source of situational ambiguity, which is how much parties know about the economic structure of the negotiation (structural 
ambiguity). We test the effects of structural ambiguity in two domains in which past research suggests gender differences in negotiation performance are likely to emerge, and hypothesize that the predicted gender differences will be greater in situations of high as compared to low structural ambiguity. In Studies 3 and 4, we test one proposed form of gender trigger, which is whether parties are representing themselves or someone else in the negotiation (representation role). We hypothesize that representation role will have a greater effect on female than on male negotiation performance. In Study 4, we test the interaction of the two moderators, hypothesizing that decreased structural ambiguity will constrain the gender effects of representation role on negotiation performance.

\section{Study 1}

In Study 1, we tested the hypothesis that structural ambiguity would moderate gender effects on MBA salary negotiations. Salary negotiations are an economically important context in which there is naturally occurring variation in structural ambiguity and there are documented gender effects on performance favoring men (Gerhart \& Rynes, 1991; Stevens, Bavetta, \& Gist, 1993). We hypothesized that the gender gap in MBA salaries would be greater in industries where there was relatively high vs. low structural ambiguity in salary negotiations.

\section{Methods}

Participants. The participants were MBA students who responded to an online job placement survey administered to graduating students in the class of 2000 by the career services office of a major American business school. There were 887 respondents (596 men, 264 women, 27 unspecified) to the survey. We deleted 27 cases where MBA sex was not specified, 57 cases due to other missing data, and 3 extreme outliers on salary. 
Because we were interested in analyzing the outcomes of salary negotiations, we removed 87 cases of individuals who reported that they were starting their own businesses, 142 cases where the MBA did not report having accepted a salary offer, and 46 cases where the same company had hired more than two MBAs and all at the same starting salary (indicating no opportunity for negotiation). The sample of data analyzed contained 525 cases (358 men, 167 women).

Survey Materials. The survey respondents provided the following information on the position they would enter after graduation: name of company, job function, industry, geographic location and the base salary offer accepted. As described in more detail below, the respondents also provided information on their work experience prior to entering the MBA program and their job search process and preferences.

Measures. We used the natural log of self-reported base salary offer accepted as our dependent measure. We created a dummy variable, Female MBA, ${ }^{1}$ which was equal to 1 if the MBA student respondent was female and 0 if male. Because our dependent variable is in $\log$ form, the coefficient on Female MBA is interpreted as the percentage difference in the salaries of female as compared to male students.

We created a second dummy variable to indicate whether the student accepted a job in a high vs. low structural ambiguity industry. Interviews with three career service professionals at the business school where we collected the data indicated that there were some industries in which MBAs had a very strong sense of the range and appropriate standards for base salary and that there were others in which they did not. Based on the information collected in the interviews and the distribution of industries in the sample, we assembled the following list of thirteen industry categories to be rated for structural 
ambiguity: investment banking, venture capital/private equity, other financial services, advertising/marketing, consulting, entertainment/media, healthcare/human services, retail, telecommunications, other services, consumer products, hi-tech and other manufacturing. We asked three career service professionals from other major American business schools who had worked with MBAs on the job market in the year 2000 to rate the degree of structural ambiguity in salary negotiations in each industry category. We collected the ratings through an online survey. For each industry category, we asked the raters to indicate their agreement with the following statement on a scale of 1-7 $(1=$ strongly disagree, 7 = strongly agree): "Class of 2000 MBAs knew exactly how much money to expect when they were discussing salary with a prospective employer in the [category inserted] industry." There was high effective reliability among the judges, Spearman Brown $R=.80$ (Rosenthal \& Rosnow, 1991). We used a median split of the ratings to separate industry categories into high vs. low ambiguity $(M d n=5.33)$. The high ambiguity industry categories (in order of increasing ambiguity) were telecommunications, other financial services (e.g., commercial banking, real-estate finance), health/human services, other manufacturing (e.g., agribusiness, industrial/transportation equipment), other services (e.g., computer services, transportation), advertising/marketing, retail and entertainment/media (percent of sample $=.31$; rating $M=4.50, \operatorname{Max}=5.33, \operatorname{Min}=3.33$ ). The low ambiguity industry categories (in order of increasing ambiguity) were investment banking, consulting, consumer products, venture capital/private equity and high technology (percent of sample $=.69$; rating $M=6.20, \operatorname{Max}=6.67, \operatorname{Min}=5.67)$. 
In order to reduce the potential for omitted variable bias when testing for gender effects on salary, we employed a total of 33 control variables representing five categories of potential salary predictors: job function, pre-MBA work experience, job market activity, geographic location of position, and job preferences. We did not control for industry because we had already used the industry categories to create the structural ambiguity variable and because there was extremely high collinearity with the job function variables (e.g., consulting industry, consulting function). We controlled for job function using dummy variables for each of the following seven job function categories: business development, consulting, general management, finance, marketing, venture capital/private equity or other job functions (i.e., remaining $6 \%$ of sample not captured by other categories). The pre-MBA work experience variables included years worked, preMBA salary and two dummy variables indicating whether the student was returning to a pre-MBA job function or industry (function experience, industry experience). The three controls for job market activity were pre-MBA employer (dummy variable equal to 1 , if returning to pre-MBA employer), number of offers received and job search activity. Job search activity consisted of the composite mean of the number of job letters the MBA sent out and the number of interviews received. Because the two variables were so highly correlated $(r=.82)$, we combined them into one variable $(\alpha=.80)$. We controlled for the geographic location of the position with dummy variables indicating whether the student had accepted a position in a major U.S. city, Europe or another location. The job preference controls were 16 dummy variables indicating whether or not the MBA had ranked each of the following concerns among their top-three job search priorities: debt payment, salary, equity/options, dual-career couple considerations, work/life balance, 
growth potential in company, expand experience, job content/level of responsibility, geography, people/company culture, obligation to previous employer, past experience at company, wanted company type (e.g., dot com), wanted function, wanted industry, and other (filled in by respondent; $5 \%$ of sample).

Results

Table 1 displays descriptive statistics for salary by sex of MBA and structural ambiguity. ${ }^{2}$ The average salary accepted by male MBAs in the sample was $\$ 5,941$ higher than the average salary accepted by female MBAs, $t(436)=3.69, p<.001, d=.31$ (equal variances not assumed). ${ }^{3}$ (There was higher variance in the salaries accepted by male as compared to female MBAs, Levene's $F=7.71, p<.01$.)

There was no significant difference in either mean or variance between the salaries in high vs. low structural ambiguity industries, $t(523)=0.91, p=.36, d=.09$ and Levene's $F=1.81, p=.18$. The lack of difference in variance indicates that the effect of structural ambiguity on gender differences in salaries is not attributable to significantly diminished variance in low as compared to high structural ambiguity industries.

Men were significantly more likely than women to accept positions in low vs. high structural ambiguity industries, $\chi^{2}(1, N=525)=8.54, p<.01$. Men were significantly more likely than women to take a position in venture capital/private equity $\left(\chi^{2}[1, N=525]=6.23, p=.01\right)$, which was a low structural ambiguity industry. Women (as compared to men) were significantly more likely to enter health/human services $\left(\chi^{2}[1\right.$, $N=525]=5.13, p=.03)$ and retail $\left(\chi^{2}[1, N=525]=5.91, p=.02\right)$, which were high structural ambiguity industries. There were no other sex differences in the industry categories $(p s>.07)$. 
There were significant sex differences in six of the 33 control variables. Consistent with the aforementioned sex differences in industry, men were significantly more likely to report venture capital/private equity as their job function than were women, $\chi^{2}(1, N=525)=7.73, p<.01$. Men were significantly more likely than women to report salary and equity/options among their top-three job search priorities, $\chi^{2}(1, N=$ $525)=6.76, p<.01$ for salary and $\chi^{2}(1, N=525)=4.85, p=.03$ for equity/options. Men (as compared to women) were also more likely to accept a position in Europe, $\chi^{2}(1, N=$ $525)=6.05, p=.01$. Women were more likely than men to accept a position in a U.S. city $\left(\chi^{2}[1, N=525]=9.08, p<.01\right)$ and to report dual-career couple considerations to be among their top-three job search priorities $\left(\chi^{2}[1, N=525]=17.96, p<.001\right)$.

Table 2 displays the results of hierarchical regression analyses of the log of salary by MBA sex and structural ambiguity. Step 1 indicated that the salaries accepted by female MBAs were $5 \%$ lower on average than those accepted by male MBAs $(t=-2.90, p$ $<.01$ ), controlling for job function, pre-MBA work experience, job market activity, geographic location and job preferences. The only statistically significant control variables were finance function $(B=-.29, t=-4.01, p<.001)$, venture capital/private equity function $(B=.19, t=2.82, p<.01)$, marketing function $(B=-.17, t=-2.81, p<$ $.01)$, pre-MBA salary $(B=.12, t=2.90, p<.01)$ and major U.S. city $(B=.17, t=3.83, p$ $<.001)$.

In Step 2 of the regression analysis, we tested the significance of the $\operatorname{sex} x$ structural ambiguity interaction. As predicted, the analyses revealed a significant sex $\times$ structural ambiguity interaction $(t=-2.00, p<.05)$, indicating a (statistically nonsignificant) $3 \%$ sex difference in low ambiguity industries as compared to a $10 \%$ sex 
difference (favoring men) in high ambiguity industries (i.e., 3\% main effect of Female MBA plus 7\% interaction effect of Female MBA $\times$ High Structural Ambiguity; $t=3.44$, $p<.001)$. The control variables maintained their significance levels.

\section{Discussion}

The results of Study 1 show that structural ambiguity moderates the effects of gender on economically important negotiation outcomes. We tested the effects of structural ambiguity on MBA salary negotiations using a dataset that enabled us to control for an extensive set of potential salary predictors, including the job function and geographic location of the position, the candidates pre-MBA salary and work experience, how many job letters were sent and interviews and offers received, and the candidates' top job preferences (e.g., high compensation, dual-career concerns, work-life balance, etc.). After controlling for these factors, we found that female MBAs accepted salary offers that were $5 \%$ lower on average than the offers accepted by male MBAs. This initial finding is consistent with previous research on MBA salary negotiations (Gerhart \& Rynes, 1991; Stevens et al., 1993). What this study contributes to the existing literature is a demonstration that the effect of gender on MBA salary negotiations is contingent on the degree of uncertainty about the potential range and appropriate standards for agreement (structural ambiguity). Our regression analyses showed no significant sex effect on the salary offers accepted by MBAs in low structural ambiguity industries - approximately $70 \%$ of the sample. However, in high structural ambiguity industries, the gender gap in starting salaries approached $\$ 10,000$, even after controlling for the wide array of salary predictors. 
While Study 1 lends external validity to the proposition that situational ambiguity moderates gender effects in negotiation, there are important limitations to this type of field research. We measured structural ambiguity at the industry level, which does not allow us to account for individual or firm-level variation in MBAs' knowledge of the bargaining range and standards for agreement in salary negotiations (Belliveau, in press). Furthermore, while salaries are generally negotiable, we do not know whether there was an opportunity for negotiation in all of the cases analyzed. We removed cases in which it appeared that recruiters had set fixed starting salaries, but we did not have the information to control for how negotiable the salaries were.

Another possible point of concern is the finding that male MBAs were significantly more likely than female MBAs to accept positions in industries with low structural ambiguity. However, this would only bias our results if gender and selfselection were both systematically related to the quality of graduates. This alternative explanation seems unlikely, particularly given the extensive of set of control variables (e.g., on job market activity, job preferences and pre-MBA salary) in our regressions.

In Study 2, we attempt to remedy some of these limitations by manipulating directly the effects of structural ambiguity at the individual level and in an experimental context in which we could randomly assign participants to conditions and control the range of possible agreement.

Study 2

In Study 2, we conducted an experimental test of the effects of structural ambiguity on gender differences in negotiation expectations and performance in a stereotypically masculine, competitive negotiation. Previous research has demonstrated 
that competitive bargaining is more strongly associated with male (vs. female) negotiating strengths (Kray et al., 2001; Stuhlmacher \& Walters, 1999) and behavior (Walters et al., 1998). It is a context in which negotiators who fulfill masculine stereotypes (e.g., being assertive, dominant, forceful, individualistic) are likely to outperform those who negotiate in a more stereotypically feminine manner (e.g., being sensitive to the needs of others, sympathetic, understanding, yielding) (Bakan, 1966; Bem, 1974). Because of the alignment of competitive bargaining with masculine behavior and performance advantages, it is a domain in which gender differences in expectations and performance are likely to favor men over women (Beyer, 1990; Beyer \& Bowden, 1997; Kray et al., 2001; Lenney, 1977). We predict that these gender differences will be greater under high as compared to low structural ambiguity.

To test our hypotheses, we used a 2 (sex of buyer) $\times 2$ (high vs. low structural ambiguity for buyer) factorial design, and manipulated structural ambiguity by altering the price comparison information available to the buyers in a single-issue price negotiation. Participants negotiated in mixed-sex pairs. In the low structural ambiguity condition, the buyers knew their negotiating limit and had clear and specific information about what would be a good agreement price in the negotiation. In the high structural ambiguity condition, the buyers knew their negotiating limit but had no price comparison information. The degree of structural ambiguity for sellers was held constant across conditions.

\section{Methods}

Participants. Participants were 214 adults (107 men, 107 women) recruited from university campuses. We removed four mixed-sex pairs from the analysis because of 
evident lack of understanding of the negotiation instructions (e.g., due to language barriers).

Materials. The simulation involved a negotiation between a motorcycle manufacturer (buyer) and a supplier (seller) over the price per unit of halogen headlights (an adapted version of Sebenius, 1996). The scenario is written as a negotiation between two male executives in the automotive industry - an industry in which almost $90 \%$ of executives are male (Catalyst, 2002). Heightening the competitive character of the negotiation, the confidential instructions emphasized to participants that the only issue for negotiation was the price per unit and that there was no potential for future business dealings with their negotiation counterparts.

The set of possible negotiated outcomes was bounded by the seller's $\$ 10 /$ unit cost of production and the buyer's alternative to fill the order through another supplier at \$35/unit. Confidential instructions informed the parties of their own but not the other side's negotiating limit (i.e., buyer's maximum willingness to pay and seller's minimum willingness to accept).

We embedded the experimental manipulation in the buyers' confidential instructions. In the low ambiguity condition, the buyers' instructions stated that their negotiating limit was $\$ 35 /$ unit and that the buyer's superior "hoped that you would be able to negotiate a deal for $\$ 15 /$ unit." In the high ambiguity condition, the buyers' instructions had no specific price references other than the $\$ 35 /$ unit negotiating limit. All sellers received the same confidential instructions, indicating that their negotiating limit was $\$ 10 /$ unit and suggesting that they should be delighted by any agreement in the range of $\$ 30 /$ unit. In sum, we manipulated structural ambiguity on the buyer's side by 
providing (low ambiguity) or withholding (high ambiguity) an external comparison standard for determining a good price in the negotiation (i.e., the superior's target of $\$ 15 /$ unit). We controlled the level of structural ambiguity on seller's side by providing all sellers with the same negotiating limit and target price information across conditions.

Procedure. At the beginning of the session, the experimenter distributed packets containing confidential instructions and the pre- and post-negotiation surveys. The experimenter was blind to the ambiguity condition, but distributed packets discretely by sex of participant in order to maximize the number of mixed-sex pairs. Participants had twenty minutes to read the confidential instructions and to answer questions about their target price per unit and intended initial offer. (See Appendix for wording of pre- and post-negotiation survey questions.) The experimenter collected all prenegotiation surveys before pairing up the participants to negotiate. Any randomly matched pairs who happened to know each other before entering the study were reshuffled to negotiate with unfamiliar partners. Participants negotiated face-to-face for a maximum of twenty minutes. Once participants finished negotiating, they completed a post-negotiation survey indicating how many minutes they negotiated, whether they reached agreement, and, if so, at what price per unit.

All participants received a $\$ 10$ show-up fee and earned a minimum of $\$ 5$ for participating in the negotiation. If participants reached agreement, they received an additional 60 cents for every dollar per unit they improved upon their negotiating limit. The experimenter gave all participants a debriefing sheet and paid them in cash at the end of the session. 
Results

All pairs reached agreement. There were no conflicts in the agreement prices reported by the buyer and seller in each negotiating pair. There was no significant difference in minutes negotiated under high structural ambiguity $(M=7.84, S D=5.32)$ as compared to low structural ambiguity $(M=8.20, S D=5.35), t(98)=0.34, p=.74, d=$ .07. (Three pairs did not report how long they had negotiated.) We analyzed indicators of prenegotiation expectations at the individual level and agreement prices at the level of the negotiating pair. Levene's test for equality of variances showed no significant differences across ambiguity conditions for any of the dependent measures $\left(F_{\mathrm{s}}<2.40, p \mathrm{~s}>.12\right)$.

The two measures of prenegotiation expectations were strongly correlated $(r=$ $.58)$, so we combined them in a composite indicator of prenegotiation expectations $(\alpha=$ $.73)$ to test for a significant interaction effect of sex of buyer $\times$ structural ambiguity on prenegotiation expectations. As predicted, we observed a significant interaction effect for sex of buyer $\times$ structural ambiguity on negotiation expectations, $F(1,99)=4.25, p=.04$, $\eta^{2}=.04$. We also observed a significant interaction of sex of buyer $\times$ structural ambiguity on agreement price, $F(1,99)=5.75, p=.02, \eta^{2}=.06$.

Figure 1 provides a graphical summary of the mean sex differences across conditions. As can be seen in Figure 1, the pattern of means observed across conditions was consistent with our predictions. In the high structural ambiguity condition, female buyers entered the negotiation with higher (less optimistic) expectations than did male buyers, and departed the negotiation having paid more than did male buyers. Under high ambiguity, there was a borderline significant sex difference in target (male $M=25.98, S D$ $=4.67$, female $M=28.52, S D=4.09, t[45]=1.98, p=.05, d=.58)$ and significant sex 
differences in intended initial offer (male $M=19.31, S D=6.37$, female $M=22.96, S D=$ $5.71, t[46]=2.09, p=.04, d=.60)$ and agreement price per unit (male $M=23.13, S D=$ 5.22 , female $M=29.38, S D=3.19, t[46]=5.00, p<.01, d=1.44)$. In the low structural ambiguity condition, there were no significant sex differences in target price (male $M=$ 19.36, $S D=4.93$, female $M=18.62, S D=5.61, t[53]=-0.53, p=.60, d=-.14)$, intended initial offer (male $M=15.17, S D=6.44$, female $M=14.46, S D=4.53, t[53]=-0.47, p=$ $.64, d=-.13$ ) or agreement price (male $M=23.47, S D=4.47$, female $M=25.41, S D=$ $4.97, t[53]=1.53, p=.13, d=.41)$.

\section{Discussion}

Study 2 provides experimental support for the hypothesized effect of structural ambiguity as a moderator of gender effects in negotiation. In a stereotypically masculine, competitive bargaining situation, gender differences favoring men in negotiation expectations and performance were significantly greater under high as compared to low structural ambiguity. Under high ambiguity, male buyers entered the negotiation expecting to pay $10 \%$ less and to offer $19 \%$ less than did female buyers. Consistent with expectations, male buyers walked out of the negotiation paying $27 \%$ less than did female buyers. However, with the benefit of clear price comparison information in the low structural ambiguity condition, there were no significant sex differences in target prices, intended first offers, or negotiated outcomes. Employing a relatively subtle manipulation of structural ambiguity that controlled for perceptions of the bargaining range and changed only the negotiators' information about appropriate standards for agreement, we found that reduced structural ambiguity was associated with significantly diminished gender differences in competitive bargaining. 
In Studies 1 and 2, we showed that decreasing the degree of situational ambiguity constrained the effects of gender on negotiation performance. In Study 3, we tested whether representation role would moderate the effect of gender on negotiation performance by acting as a form a gender trigger that produced divergent situational responses as a function of gender.

\section{Study 3}

In Study 3, we tested the hypothesized effects of representation role as a gender trigger in negotiation in a 2 (sex of seller) $\times 2$ (self- vs. other- representation for seller) factorial design. All of the buyers in the negotiation were male. The scenario involved negotiating the compensation for an internal candidate for a new management position within a corporation. In the self-representation condition, the seller adopted the role of the candidate. In the other-representation condition, the seller adopted the role of the candidate's mentor and negotiated on behalf of the candidate. We hypothesized that female sellers would set higher compensation targets and negotiate higher compensation agreements when they were negotiating on behalf of the candidate as compared to when they were negotiating for themselves. We predicted that the representation role manipulation would have a greater effect on female than on male sellers.

\section{Methods}

Participants. We collected data from 176 executive training program participants (124 men, 52 women). The participants were senior executives from private-sector enterprises and government agencies. Representative titles included chairman, chief executive officer, chief operating officer, director, deputy director, president, vice 
president and general manager. As explained below, we removed three pairs from the analysis, leaving a total sample of 170 participants (120 men, 50 women).

Materials. The simulation involved a negotiation over compensation for an internal job candidate for the position of director of product marketing in a medium-sized software company (an adapted version of McGinn \& Pradel, 2004). The buyer is the vice president in charge of product management and marketing. The seller is either the job candidate (self-representation condition) or the candidate's mentor (other-representation condition). The director of marketing position would be a lateral transfer for the candidate from the sales to the marketing department. The mentor is the head of the sales department. Confidential instructions explained that the position was created especially for the candidate by the vice president, following conversations with the candidate and the candidate's mentor. Confidential instructions made clear that the buyer would have ongoing relationships with the candidate and mentor, regardless of the outcome of the negotiation. The candidate's best alternative is an offer for a position with the professional services department of the same company.

In order to enhance the degree of structural ambiguity within the negotiation context, the confidential instructions contained no clear reference points for determining the limits of the bargaining range or appropriate standards for agreement. The candidate's alternative offer from the professional services department was estimated at approximately $\$ 145,000$ including salary and bonus, but the confidential instructions emphasized that the professional services position was less attractive to the candidate than was the marketing position and that compensation standards in professional services were different than in marketing. Because of the lack of comparability between the two 
positions, the sellers did not have a clear external standard to use in setting their negotiating limits. The confidential instructions for the buyer included some background information on typical starting salaries for product managers at the company $(\$ 100,000$ $\$ 120,000)$ and in the industry $(\$ 70,000-\$ 140,000)$, but also noted that product manager is a lower-level position than director of marketing and that the candidate is exceptional. In this way, the buyer was not bound by these standards, and could set whatever (monetary) compensation level he deemed appropriate.

The representation role manipulation was embedded in the sellers' confidential instructions. The sellers received confidential instructions indicating either that they were the candidate themselves or the mentor (head of the sales department). In both cases, their task was to negotiate the compensation that the candidate would receive in the director of marketing position. With the exception of references to the candidate or mentor being in either the second or third person, the confidential instructions for the sellers were identical across representation conditions. All buyers received the same confidential instructions. In order to provide some context for the representation role manipulation, the buyers' instructions indicated that, "It's not clear to you whether you'll be meeting with [the candidate] and [the mentor], or with just one of them." All roles had genderambiguous names, and the text contained no gender-specific pronouns referencing the negotiating parties.

Procedure. The participants received packets of information containing a coversheet, an individual prenegotiation survey, confidential instructions, and a joint post-negotiation survey (attached to the back of buyers' confidential instructions). The coversheet informed them of their pairing number and role in the negotiation and directed 
them not to include non-monetary incentives in their terms of agreement. Participants reported on the prenegotiation survey the best agreement they hoped to negotiate in terms of total annual compensation (target compensation). On the joint post-negotiation survey, participants reported whether they had reached agreement and, if so, what would be the total annual compensation that the candidate would receive. To confirm that the sellers had enacted their roles consistent with the representation role manipulation, the buyers reported whether they had negotiated with the candidate or the mentor. (See Appendix for wording of pre- and post-negotiations questions.)

The researchers collected the prenegotiation surveys in class before the participants learned with whom they would negotiate. Following the negotiation, the participants reported their negotiation outcomes on the joint post-negotiation survey. The researchers collected the completed post-negotiation surveys before the participants returned to the classroom to debrief their negotiation experiences.

Results

We removed three pairs before analyzing the data: one had failed to report whether the seller was the candidate or the mentor, another misidentified the seller's representation role, and the third reported an incalculable commission-based compensation agreement. All buyers in the sample of data analyzed reported correctly whether the seller had negotiated as the candidate (self-representation) or mentor (otherrepresentation). We analyzed prenegotiation targets at the individual level and negotiation outcomes at the level of the negotiating pair.

Thirty-eight percent of the pairs failed to reach agreement, and there was a significant main effect by sex of seller on the agreement rate. Female sellers were 
significantly more likely to reach agreement than were male sellers, female $P=.74$ and male $P=.46, \chi^{2}(1, N=85)=7.02, p<.01$. The representation role manipulation had no significant effect on the agreement rate, self-representation $P=.61$ and other-

representation $P=.64, \chi^{2}(1, N=85)=0.09, p=.76$. Logit regression analyses showed no significant interaction between the sex of the seller and representation role on agreement rate, $z=0.73, p=0.47$.

Contrary to expectations, there was no significant interaction between sex of seller and representation role on prenegotiation expectations, $F(1,81)=1.37, p=.25, \eta^{2}$ $=.02$. The representation role manipulation had no significant effect on the target compensation reported by female sellers (self-representation $M=\$ 173,000, S D=$ $\$ 37,819$; other-representation $M=\$ 171,000, S D=\$ 30,482), t(48)=-0.20, p=.84, d=-$ .06. Representation role also had no significant effect on the targets reported by male sellers (self-representation $M=\$ 174,167, S D=\$ 38,966$; other-representation $M=$ $191,118, S D=\$ 39,528), t(33)=1.28, p=.21, d=.43$. Target compensation levels were significantly correlated with agreement values for both male and female sellers, female sellers $r=.43, p<.01$ and male sellers $r=.55, p=.03$.

We used an ANCOVA model to test the significance of the representation role manipulation on negotiated outcomes, controlling for the variance associated with prenegotiation expectations. As hypothesized, the results revealed a significant interaction between sex of seller and representation role on agreement compensation, $F(1,47)=5.26, p=.03, \eta^{2}=.10$. Female sellers negotiated significantly higher compensation in the other- vs. self-representation condition $\left(F[1,33]=4.89, p=.03, \eta^{2}=\right.$ 
$.13)$, while the effect of representation role for men remained non-significant $(F[1,12]=$ $\left.1.06, p=.32, \eta^{2}=.08\right)$

In order to confirm that the results on negotiated outcomes were not biased by the higher agreement rate among female than male sellers, we used a statistical measure developed by Heckman (1979) that jointly estimates an equation for who reaches agreement and for the amount of the negotiated agreement, with the latter equation being corrected for the biased sample. When we use this procedure, the effect of the interaction between sex of seller and representation role on agreement compensation remains significant, $z=2.73, p<.01$.

As illustrated in Figure 2, negotiation performance across conditions followed the predicted pattern. As hypothesized, the representation role manipulation had a significantly positive effect on the compensation agreements negotiated by female sellers. Female sellers negotiated mean compensation agreements for $\$ 141,643(S D=\$ 26,585)$ when representing themselves and for $\$ 167,250(S D=\$ 48,121)$ when representing the candidate, $t(35)=2.07, p<.05, d=.69$. The representation role manipulation had no significant effect on male sellers' performance. Male sellers negotiated mean compensation agreements for $\$ 146,093(S D=\$ 26,828)$ when representing themselves and for $\$ 146,667(S D=\$ 10,897)$ when representing the candidate, $t(14)=0.05, p=.95$, $d=.03$.

\section{Discussion}

Study 3 supports the hypothesis that representation role is a gender trigger in negotiation, by demonstrating that the shift in perspective from negotiating for oneself to advocating for someone else has a significantly greater effect on female than on male 
performance. Female executives negotiated compensation agreements that were $18 \%$ higher when they were representing someone else as opposed to themselves, whereas there was less than a one half of one percent difference in the performance of male executives across the representation role conditions.

Contrary to our expectations, the representation role manipulation had no effect on the target compensation values reported by female executives. Our hypothesis that representation role would function as a gender trigger in negotiation was motivated by three bodies of literature (discussed earlier) on entitlement, backlash, and gender and interdependent self-construal. The entitlement literature, in particular, would suggest that women might enter compensation negotiations with lower expectations for themselves than for others (Callahan-Levy \& Messe, 1979; Major, McFarlin et al., 1984) and that those relatively depressed compensation levels would lead to lower compensation agreements (Major, Vanderslice et al., 1984). The results of this experiment suggest that entitlement does not explain the effect of representation role on women's negotiation performance.

The finding that women were more effective advocates than self-promoters during the negotiation is consistent with both the literatures on backlash and on gender and interdependent self-construal. The literature on backlash suggests that women may be resisted more strongly by their counterparts when negotiating for themselves, because self-promotion is a stereotypically male (agentic) behavior that contradicts communal prescriptions for female behavior (Rudman, 1998; Rudman \& Glick, 1999). However, if this were the case, we would expect to find the women in the self-representation 
condition doing particularly poorly as compared to male or female negotiators in the other conditions, and that is not the pattern of effects that we observe.

The pattern of means depicted in Figure 2 more strongly supports the predictions of the literature on gender and interdependent self-construal (Cross \& Madson, 1997). As opposed to being held back when negotiating for themselves, Cross and Madson's theory suggests that women would be particularly energized in negotiations in which they felt a personal sense of responsibility or obligation to represent the interests of another person. The female executives in the other-representation condition appeared to be the most motivated among all sellers, attaining compensation agreements that were $16.4 \%$ higher on average than those negotiated by all other participants.

In Study 4, we conducted a more conservative test of the effect of representation role on negotiation performance, in which participants were paid based on their performance and performance incentives were held constant across conditions. The only difference between the self- and other-representation conditions was whether the negotiator had responsibility for negotiating the payoff for another person.

Finally, our theory would suggest that gender triggers would have a stronger effect under high as compared to low structural ambiguity. In Study 3, we did not manipulate structural ambiguity, but we did take steps to enhance the structural ambiguity of the situation by providing multiple subjective and objective reference points (as opposed to one clear comparison standard) for determining what should be the parties' negotiating limits and aspirations. In Study 4, we manipulate structural ambiguity to test whether decreased ambiguity dampens the gender effects of representation role on negotiation performance. 
Study 4

In Study 4, we tested whether structural ambiguity would moderate the effect of representation role as a gender trigger in negotiation. We employed a 2 (high vs. low structural ambiguity for seller $) \times 2($ sex of seller $) \times 2$ (self- vs. other-representation for seller) factorial design. All of the negotiating dyads were mixed-sex pairs. The simulation involved negotiating the hourly wage for a student who was contracting for part-time work through an employment agency. Sellers in the self-representation condition adopted the role of the student and negotiated their own hourly wage. Sellers in the otherrepresentation condition adopted the role of agency owner and negotiated the hourly wage to be paid to the student. Each seller in the other-representation condition represented another study participant in the negotiation. Participants were paid based on their own or their negotiation representative's performance.

In order to restrict the manipulation to a shift in social role, we held the sellers' economic incentives constant across conditions. All sellers negotiated for a higher payoff for themselves. The only difference between the self- and other-representation conditions in terms of monetary payoff was that the sellers in the other-representation condition were also negotiating for a higher payoff for another study participant. (See details in Methods section, below.) In this way, the representation role manipulation did not affect how much the sellers would benefit personally from their performance in the negotiation; it only affected whether their performance affected the welfare of another person.

We manipulated structural ambiguity by altering the wage comparison information available to the sellers prior to the negotiation. In the low ambiguity condition, the sellers knew their negotiating limit and had clear and specific wage 
comparison information. In the high ambiguity condition, the sellers knew their negotiating limit but had no wage comparison information. The degree of structural ambiguity for the buyers was held constant across conditions.

\section{Hypotheses}

We hypothesized that structural ambiguity would moderate the effect of representation role as a gender trigger in negotiation. We expected, therefore, to observe a significant three-way interaction of structural ambiguity $\times$ sex of seller $\times$ representation role on agreement wage. We hypothesized that the gender effects of representation role would be greater under high as compared to low structural ambiguity. We expected therefore to observe a significant two-way interaction of sex of seller $\times$ representation role on wage under high ambiguity, and for the effect of that two-way interaction to be diminished under low structural ambiguity.

For female sellers, we predicted that the positive effect of the shift from negotiating solely for oneself (self-representation) to having responsibility for advocating for someone else (other-representation) would be greater under high as compared to low structural ambiguity. We expected therefore to observe a significant two-way interaction of representation role $\times$ structural ambiguity for female sellers and for the pattern of means to show a more positive advantage of negotiating for other vs. self under high as compared to low structural ambiguity. For male negotiators, we had no reason to expect that a difference in representation role would affect their performance under high or low structural ambiguity. 


\section{Methods}

Participants. Participants were 315 university students (147 men, 168 women) recruited from college campuses. One hundred and twenty-six mixed-sex pairs participated in the negotiation. Sixty-three participants completed an alternative coding task while another participant represented them during the negotiation. We dropped two pairs from the sample due to evident misunderstanding of the negotiation instructions and 10 cases due to incomplete data.

Materials. The simulation, written for this experiment, involved a single-issue negotiation over the hourly compensation for a student for 20 hours of work redesigning the website of a small catering company. According to the scenario, the prospective client seeks to contract the student through an agency that guarantees high-quality computer services at low cost by recruiting talented undergraduates. The student is a college senior, and the agency owner is a recent college graduate. The set of possible agreements was bounded by the minimum acceptable wage to the agency ( $\$ 30 /$ hour) and the prospective client's best alternative offer for 20 hours of work by a freelancer ( $\$ 55 /$ hour). All roles had gender ambiguous names, and the texts contained no gender-specific pronouns. Confidential instructions informed the parties of their own but not the other side's negotiating limit. We embedded the representation role and structural ambiguity manipulations in the sellers' confidential instructions.

The sellers received confidential instructions indicating either that they were the student (self-representation) or the agency owner (other-representation). In both cases, their task was to negotiate the hourly wage that the student would receive for work on the website. Confidential instructions informed all sellers that their payoff for the 
experimental session depended on their performance in the negotiation. In order to hold economic incentives constant across conditions, all sellers (students and agency owners) received 50 cents for every dollar they gained on the wage above the $\$ 30 /$ hour minimum. According to the negotiation scenario, the other 50 cents of every dollar went to the agency owner if they were the student or to the student if they were the agency owner. In the other-representation condition only, the confidential instructions informed the sellers that their negotiation performance would also determine the payoff of another study participant whom they would represent in the negotiation and who would remain anonymous. Participants who were represented during the negotiation earned as much as the negotiator representing them.

We manipulated structural ambiguity either by providing wage comparison information (low ambiguity) or by withholding any wage comparison information (high ambiguity). In the low structural ambiguity condition, confidential instructions informed the sellers that their negotiating limit was $\$ 30 /$ hour and that the agency owner estimated that the catering company (the buyer), "would have to pay at least $\$ 40$ per hour to get a freelancer to do the job." The $\$ 40$ standard was based on the results of pretests of the high ambiguity condition, which produced an average wage of $\$ 39.95 /$ hour. In the high ambiguity condition, the sellers' instructions contained no specific wage references other than the $\$ 35 /$ unit negotiating limit.

The prospective clients (buyers) had the same negotiation information across all conditions, with one exception. In order to avoid confusion about the identity of the seller, the buyers' confidential instructions indicated whether they would negotiate with the student or the agency owner. We controlled the level of structural ambiguity on the 
buyer's side by providing all buyers with the same price comparison information and negotiating limit. Buyers read in their confidential instructions that, "A friend of yours contracted with [the agency] recently and paid $\$ 45$ per hour. You would ideally like to pay $\$ 40$ or less, but you absolutely will not pay any more than $\$ 55$ per hour for [the student's] work on the website."

Procedure. In the course of obtaining the subjects' consent to participate, the experimenter explained that some participants would take part in a negotiation and that some would be represented in a negotiation by another participant in the study who would remain anonymous. The experimenter explained that those who did not negotiate would complete an alternative task and their payment for the session (apart from the show-up fee) would depend on the performance of their representative in the negotiation.

The experimenter distributed packets containing participant numbers, confidential instructions and pre- and post-negotiation surveys. (See Appendix for wording of preand post-negotiation survey questions.) The experimenter was blind to the manipulations, but distributed packets discretely by sex of participant in order to maximize the number of mixed-sex pairs. Participants had fifteen minutes to read the confidential instructions and to answer the prenegotiation questions. The experimenter collected all prenegotiation surveys before pairing participants to negotiate. Any randomly matched pairs who happened to know each other before entering the study were reassigned to negotiate with unfamiliar partners.

The negotiating pairs were spread out across a large lecture hall. Participants who were being represented in the negotiation sat in the front row of the lecture hall. Previous research has shown that knowledge of the sex of one's constituent can affect negotiation 
behavior (Pruitt et al., 1986). In order to ensure that negotiators in the otherrepresentation condition did not know the sex of the person they were representing, the experimenter made sure that there was a mix male and female participants being represented in the negotiation.

The negotiating pairs had a maximum of ten minutes to reach agreement. Once participants finished negotiating, they answered post-negotiation survey questions on how many minutes they negotiated, whether they reached agreement, and, if so, at what price per unit. The experimenter collected the post-negotiation surveys before distributing exit surveys containing demographic questions (e.g., sex, years of work experience, university affiliation) and a debriefing form.

All participants received a $\$ 10$ show-up fee and earned an additional $\$ 5$ if they arrived at least five minutes early. The sellers (agents and students) received an additional 50 cents for every dollar they improved upon their negotiating limit, and the buyers received an additional $\$ 1$ for every dollar they improved upon their negotiating limit. The experimenter paid all participants in cash at the end of the session.

\section{Results}

All pairs reached agreement. There was total concurrence in the agreement wages reported by the buyers and sellers in each of the negotiating pairs. Responses to the prenegotiation questions confirmed that all sellers knew how much they would be paid based on their performance in the negotiation and that the sellers in other-representation condition knew they were negotiating for someone else and how much that participant would earn based on their performance. Levene's test for equality of variances showed no significant difference in wages by structural ambiguity condition $(F=0.53, p=.47)$. 
There was no significant difference in minutes negotiated under high structural ambiguity $(M=6.24, S D=2.69)$ as compared to low structural ambiguity $(M=5.52, S D=2.77)$, $t(112)=-1.41, p=.16, d=.26$.

We used ANCOVA models to partial out error variance associated with participants' work experience (1 if 0-1 year, 2 if 2-5 years, 3 if 6-10 years) and educational background ( 1 if nationally top-ranked university, 0 if not, according to America's best colleges, 2001), joint significance of buyer and seller controls, $F(4,100)=$ $4.46, p<.01$. Table 3 displays the results of the test of the three-way interaction of structural ambiguity $\times$ sex of seller $\times$ representation role on agreement wages.

Consistent with our primary hypothesis that structural ambiguity would moderate the gender effect of representation role on agreement wages, ANCOVA results showed a significant three-way interaction effect of structural ambiguity $\times$ sex of seller $\times$ representation role on wages, $F(1,100)=7.54, p<.01, \eta^{2}=.07$. To explore this threeway interaction in more detail, we conducted separate ANCOVAs for the high and low ambiguity conditions. Consistent with the hypothesis that the gender effect of representation role would be greater under high than under low ambiguity, analyses showed that the two-way interaction effect of sex of seller $\times$ representation role was significant in the high structural ambiguity condition $\left(F[1,43]=6.61, p=.01, \eta^{2}=.13\right)$, but not in the low structural ambiguity condition $\left(F[1,53]=1.46, p=.23, \eta^{2}=.03\right)$.

We also conducted separate ANCOVAs by sex of seller. As predicted for female sellers, there was a significant interaction of structural ambiguity $\times$ representation role on agreement wages, $F(1,47)=6.77, p=.01, \eta^{2}=.13$. Under high structural ambiguity, female sellers negotiated significantly higher agreement wages in the other-representation 
as compared to self-representation condition, marginal estimated $M=45.39, S E=1.22$ for other-representation, marginal estimated $M=41.85, S E=1.04$ for self-representation, $F(1,20)=4.65, p=.04, \eta^{2}=.19$. Under low structural ambiguity, there was no significant impact of representation role on female sellers' agreement wages, marginal estimated $M=40.73, S E=1.08$ for other-representation, marginal estimated $M=42.72$, $S E=1.04$ for self-representation, $F(1,23)=1.74, p=.20, \eta^{2}=.07$.

Consistent with the hypothesized pattern of means, there was no significant interaction effect of structural ambiguity $\times$ representation role on wages negotiated by male sellers, $F(1,49)=1.37, p=.25, \eta^{2}=.03$. There was no significant main effect for representation role on male sellers' agreement wages in the high structural ambiguity condition (marginal estimated $M=40.66, S E=1.30$ for other-representation, marginal estimated $M=43.09, S E=1.14$ for self-representation, $F[1,19]=1.75, p=.20, \eta^{2}=.08$ ) or in the low structural ambiguity condition (marginal estimated $M=41.39, S E=0.83$ for other-representation, marginal estimated $M=41.52, S E=0.83$ for self-representation, $\left.F[1,26]=0.01, p=.92, \eta^{2}<.01\right)$

\section{Discussion}

The results of Studies 3 and 4 support the hypothesis that representation role functions as a gender trigger in negotiation. In both studies, negotiating for the welfare of another person heightened female negotiation performance as compared to negotiating solely for oneself. This finding is consistent with Cross and Madson's (1997) theory of gender and interdependent self-construal, but future research should examine directly the psychological mechanisms underlying the effects of representation role on negotiation performance. 
Study 4 also supports the proposition that situational ambiguity moderates the effect of gender triggers on negotiation. Under high structural ambiguity, representation role moderated the effect of gender on negotiation performance. Consistent with the results of Study 3, the shift from negotiating solely for oneself to negotiating for someone else significantly enhanced female negotiators' performance (by almost 9\%) but had no significant effect on male negotiators' performance. Under low structural ambiguity, however, the moderating effect of representation role diminished.

General Discussion

In combination, the four studies presented in this paper demonstrate two distinct categories of situational moderators of gender effects in negotiation. The first category, situational ambiguity, moderates the "strength" of the negotiation situation (Mischel, 1977). Decreased situational ambiguity enhances the influence of general situationspecific (as opposed to gender-specific) cues within the negotiation context, and reduces the potential for gender to influence negotiation performance. One way to modulate situational ambiguity is to manipulate the degree of uncertainty in parties' understanding of the economic structure of the negotiation (structural ambiguity). In Studies 1 and 2, we observed - both in the field and in the lab - that gender effects on negotiation performance were significantly greater under conditions of high as compared to low structural ambiguity.

It warrants emphasis that we tested the effects of structural ambiguity in two domains in which one would expect gender differences to emerge based upon past research. We are not proposing that increased situational ambiguity causes gender effects, but rather that it facilitates their emergence by weakening the influence of potentially 
competing, non-gender-specific behavioral cues. Therefore, we would not expect increased situational ambiguity to result in significant gender effects across all negotiation contexts.

The second category, gender triggers, informs the manifestation of gender effects by prompting alternative modes of response as a function of gender. Previous research has shown that there are various potential gender triggers in negotiations (Kray et al., 2002; Kray et al., 2001; Pruitt et al., 1986; Stuhlmacher \& Walters, 1999; Walters et al., 1998). In Studies 3 and 4, we demonstrated that representation role (negotiating for self or other) functions as a gender trigger by activating a stronger response in female than in male negotiators. Female negotiators' performance enhanced significantly when negotiating for someone else as opposed to only for themselves, whereas representation role had a negligible effect on the performance of male negotiators. Consistent with the notion that there are many forms of gender triggers in negotiation, it is worth noting that we operationalized representation role in terms of representing oneself as opposed to another person. Other types of representation role relationships might produce different effects. For instance, if men are more motivated by their relationships to groups than are women (Baumeister \& Sommer, 1997; Gabriel \& Gardner, 1999), representation of a group (as compared to self) might trigger a stronger effect on male than on female negotiation performance. Future research should also test the interactions of previously identified gender triggers with other individual differences. One limitation of the current research and much of the existing research on gender triggers is that the participant pools were overwhelmingly White, American and middleclass, and there was no potential to explore the cultural boundaries of the observed gender effects. 
In Study 4, we demonstrated that situational ambiguity and gender triggers are not only distinct categories of situational moderators, but that they may work in interaction to influence the effect of gender on negotiation: decreased structural ambiguity constrained the gender effects of representation role on negotiation performance. It is not clear from these results that high situational ambiguity is a necessary condition for gender triggers to have significant effects. Some gender triggers may be strong and salient enough to eclipse the non-gender specific behavioral cues in situations with low ambiguity. The results of this research suggest, however, that sharpening the specificity of non-gender specific behavioral cues is one avenue for weakening the influence of gender triggers on negotiation performance. Future research should test the limits of the interaction of situational ambiguity and gender triggers on negotiation performance, and explore more deeply the cognitive mechanisms that underlie their interactive effects.

This conceptualization of the mechanics of gender effects in negotiation as the product of factors that constrain the potential for gender effects (situational ambiguity) and others that shape their manifestation (gender triggers) has important implications for the conduct of negotiation research. Experimental settings tend, by design, to be "strong" situations and tend, therefore, to minimize potential effects of gender and other individual differences on behavior (Mischel, 1977; Snyder \& Ickes, 1985). If researchers are not sensitive to the degree of ambiguity within the negotiation situations they create, they may miss opportunities to explore the conditions under which gender influences negotiation behavior and performance. When comparing and interpreting findings across studies, researchers should take into account that variation in situational ambiguity as well as gender triggers may moderate results. 
Finally, motivated by theory on the situational moderators of personality on behavior, this conceptual framework of constraints and triggers should extend to other forms of individual differences, such as race and personality. Future research could explore, for instance, the potential triggers of race effects on negotiations and test whether the degree of situational ambiguity moderates their impact. To the extent that individual differences, such as gender and race, are associated with power and status asymmetries, this work may extend as well to the study of power in negotiation. For instance, the influence of asymmetric power relations on negotiation behavior or performance may be moderated by the degree of situational ambiguity.

\section{Conclusion}

Gender does not always matter in negotiation. Its effects are situationally bound. The results of Study 1 provide a compelling example of this. We observed no difference in the mean salaries negotiated by male and female MBAs in low structural ambiguity industries, which comprised nearly $70 \%$ of the sample. However, the effects that we did observe had material implications. After controlling for a broad range of salary predictors, there still remained a $\$ 10,000$ gender gap in MBA salaries in industries with high structural ambiguity. Assuming that MBAs graduate at age 30 and work until they are 65 and that they receive only a 3\% raise per year, the value of a gender gap in starting salary of $\$ 10,000$ amounts to a gender gap in earnings of more than $\$ 600,000$ over the course of a career. Assuming 5\% annual interest on those additional earnings, that gender gap in earnings becomes a wealth gap of $\$ 1.5$ million. Even small and situationally bound effects can have economically important implications (Eagly, 1996). 
A situational approach leads to a more nuanced understanding of gender in negotiation. It also helps to shine the spotlight on those circumstances under which prescriptive interventions are likely to be most valuable. The contribution of this research, however, goes beyond adding variables to the list of potential situational moderators of gender in negotiation. By proposing two organizing constructs for understanding how situational variables influence gender effects on negotiation, this work provides a foundation for the advancement of the study of gender in negotiation more broadly. As described above, this conceptual framework also suggests directions for development of other areas of negotiation research in which individual differences or other forms of identity markers, such as power, influence negotiation results. By moving beyond lists of moderators to organizing principles, we are better equipped to interpret and shape the influence of contextual factors on negotiation behavior and outcomes. 


\section{References}

America's best colleges. (2001). Washington, DC: U.S. News and World Report.

Bakan, D. (1966). The duality of human existence. Chicago: Rand McNally.

Baumeister, R. F., \& Sommer, K. L. (1997). What do men want? Gender differences and two spheres of belongingness: Comment on Cross and Madson (1997). Psychological Bulletin, 122(1), 38-44.

Bazerman, M. H., Neale, M. A., Valley, K. L., \& Zajac, E. J. (1992). The effect of agents and mediators on negotiation outcomes. Organizational Behavior and Human Decision Processes, 53(1), 55-73.

Belliveau, M. A. (in press). Blind ambition? The effects of social networks and institutional sex composition on the job search outcomes of elite coeducational and women's college graduates. Organization Science.

Bem, S. L. (1974). The measurement of psychological androgyny. Journal of Consulting and Clinical Psychology, 42(2), 155-162.

Bem, S. L., \& Lenney, E. (1976). Sex typing and the avoidance of cross-sex behavior. Journal of Personality and Social Psychology, 33(1), 48-54.

Benton, A. A. (1972). Accountability and negotiations between group representatives. Proceedings of the Annual Convention of the American Psychological Association, 7, 227-228.

Benton, A. A. (1975). Bargaining visibility and the attitudes and negotiation behavior of male and female group representatives. Journal of Personality, 43(4), 661-677.

Ben-Yoav, O., \& Pruitt, D. G. (1984). Accountability to constituents: A two-edged sword. Organizational Behavior and Human Decision Processes, 34(3), 283-295. 
Beyer, S. (1990). Gender differences in the accuracy of self-evaluations of performance. Journal of Personality and Social Psychology, 59(5), 960-970.

Beyer, S., \& Bowden, E. M. (1997). Gender differences in self-perceptions: Convergent evidence from three measures of accuracy and bias. Personality and Social Psychology Bulletin, 23(2), 157-172.

Brehm, J. W. (1966). A theory of psychological reactance. New York: Academic Press. Bylsma, W. H., \& Major, B. (1992). Two routes to eliminating gender differences in personal entitlement: Social comparisons and performance evaluations. Psychology of Women Quarterly, 16(2), 193-200.

Callahan-Levy, C., \& Messe, L. A. (1979). Sex differences in the allocation of pay. Journal of Personality and Social Psychology, 37(3), 433-446.

Carnevale, P. J., Pruitt, D. G., \& Britton, S. D. (1979). Looking tough: The negotiator under constituent surveillance. Personality and Social Psychology Bulletin, 5(1), $118-121$.

Catalyst census of women corporate officers and top earners of the Fortune 500. (2002). New York: Catalyst.

Croson, R., \& Mnookin, R. H. (1997). Does disputing through agents enhance cooperation? Experimental evidence. Journal of Legal Studies, 26, 331-345.

Cross, S. E., \& Madson, L. (1997). Models of the self: Self-construals and gender. Psychological Bulletin, 122(1), 5-37.

Deaux, K., \& LaFrance, M. (1998). Gender. In D. T. Gilbert, S. Fiske \& G. Lindsey (Eds.), The handbook of social psychology (4th ed., pp. 788-827). Boston: McGraw-Hill. 
Deaux, K., \& Major, B. (1987). Putting gender into context: An interactive model of gender-related behavior. Psychological Review, 94(3), 369-389.

Dovidio, J. F., Ellyson, S. L., Keating, C. F., \& Heltman, K. (1988). The relationship of social power to visual displays of dominance between men and women. Journal of Personality and Social Psychology, 54(2), 233-242.

Druckman, D., Solomon, D., \& Zechmeister, K. (1972). Effects of representational role obligations on the process of children's distribution of resources. Sociometry, 35(3), 387-410.

Eagly, A. H. (1987). Sex differences in social behavior: A social-role interpretation. Hillsdale, NJ: Erlbaum.

Eagly, A. H. (1996). Differences between women and men: Their magnitude, practical importance, and political meaning. American Psychologist, 51(2), 158-159.

Eagly, A. H., Makhijani, M. G., \& Klonsky, B. G. (1992). Gender and the evaluation of leaders: A meta-analysis. Psychological Bulletin, 111(1), 3-22.

Frey, R. L., \& Adams, J. S. (1972). The negotiator's dilemma: Simultaneous in-group and out-group conflict. Journal of Experimental Social Psychology, 8(4), 331-346.

Gabriel, S., \& Gardner, W. L. (1999). Are there 'his' and 'hers' types of interdependence? The implications of gender differences in collective versus relational interdependence for affect, behavior, and cognition. Journal of Personality and Social Psychology, 77, 642-655.

Gerhart, B., \& Rynes, S. (1991). Determinants and consequences of salary negotiations by male and female MBA graduates. Journal of Applied Psychology, 76(2), 256262. 
Haccoun, R. R., \& Klimoski, R. J. (1975). Negotiator status and accountability source: A study of negotiator behavior. Organizational Behavior and Human Decision Processes, 14(3), 342-359.

Heckman, J. J. (1979). Sample selection bias as a specification error. Econometrica, 47(1), 153-162.

Kray, L. J., Galinsky, A., \& Thompson, L. (2002). Reversing the gender gap in negotiations: An exploration of stereotype regeneration. Organizational Behavior and Human Decision Processes, 87(2), 386-409.

Kray, L. J., \& Thompson, L. (in press). Gender stereotypes and negotiation performance. In B. M. Staw \& R. Kramer (Eds.), Research in Organizational Behavior (Vol. 26). Greenwich, CT: JAI Press.

Kray, L. J., Thompson, L., \& Galinsky, A. (2001). Battle of the sexes: Gender stereotype confirmation and reactance in negotiations. Journal of Personality and Social Psychology, 80(6), 942-958.

Lax, D., \& Sebenius, J. (1986). The manager as negotiator: Bargaining for cooperation and competitive gain. New York: Free Press.

Lenney, E. (1977). Women's self-confidence in achievement settings. Psychological Bulletin, 84(1), 1-13.

Maccoby, E. (1990). Gender and relationships. American Psychologist, 45(4), 513-520.

Major, B., \& Konar, E. (1984). An investigation of sex differences in pay expectations and their possible causes. Academy of Management Journal, 27(4), 777-792. 
Major, B., McFarlin, D. B., \& Gagnon, D. (1984). Overworked and underpaid: On the nature of gender differences in personal entitlement. Journal of Personality and Social Psychology, 47(6), 1399-1412.

Major, B., Vanderslice, V., \& McFarlin, D. B. (1984). Effects of pay expected on pay received: The confirmatory nature of initial expectations. Journal of Applied Social Psychology, 14(5), 399-412.

McGinn, K., \& Pradel, D. (2004). RetailMax (A) and (B). Boston: Harvard Business School.

Mischel, W. (1977). The interaction of person and situation. In D. Magnusson \& N. S. Endler (Eds.), Personality at the crossroads: Current issues in interactional psychology. Hillsdale, NJ: Erlbaum.

Mnookin, R. H., \& Susskind, L. E. (Eds.). (1999). Negotiating on behalf of others: Advice to lawyers, business executives, sports agents, diplomats, politicians and everybody else. Thousand Oaks, CA: Sage.

Neale, M. A., \& Bazerman, M. H. (1991). Cognition and rationality in negotiation. New York: The Free Press.

Parks, J. M., \& Conlon, E. J. (1995). Compensation contracts: Do agency theory assumptions predict negotiated agreements? Academy of Management Journal, $38(3), 821-838$.

Pruitt, D. G., Carnevale, P. J., Forcey, B., \& Van Slyck, M. (1986). Gender effects in negotiation: Constituent surveillance and contentious behavior. Journal of Experimental Social Psychology, 22(3), 264-275. 
Raiffa, H. (1982). The art and science of negotiation. Cambridge, MA: Harvard University Press.

Rosenthal, R., \& Rosnow, R. L. (1991). Essentials of behavioral research: Methods and data analysis. New York: McGraw-Hill.

Rubin, J. Z., \& Brown, B. R. (1975). Bargainers as individuals. In The social psychology of bargaining and negotiation (pp. 157-196). New York: Academic Press.

Rubin, J. Z., \& Sander, F. (1988). When should we use agents? Direct vs. representative negotiations. Negotiation Journal, 4, 395-401.

Rudman, L. A. (1998). Self-promotion as a risk factor for women: The costs and benefits of counterstereotypical impression management. Journal of Personality and Social Psychology, 74(3), 629-645.

Rudman, L. A., \& Glick, P. (1999). Feminized management and backlash toward agentic women: The hidden costs to women of a kinder, gentler image of middle managers. Journal of Personality and Social Psychology, 77(5), 1004-1010.

Schelling, T. C. (1980). The strategy of conflict. Cambridge, UK: Harvard University Press.

Sebenius, J. K. (1996). Mapletech-Yazawa (A) and (B). Boston: Harvard Business School.

Skrypnek, B. J., \& Snyder, M. (1982). On the self-perpetuating nature of stereotypes about women and men. Journal of Experimental Social Psychology, 18(3), 277291. 
Snyder, M., \& Ickes, W. (1985). Personality and social behavior. In G. Lindzey \& E. Aronson (Eds.), Handbook of social psychology (3rd ed., Vol. 2, pp. 883-947). New York: Random House.

Steele, C. M. (1997). A threat in the air: How stereotypes shape intellectual ability and performance. American Psychologist, 52(6), 613-629.

Stevens, C. K., Bavetta, A. G., \& Gist, M. E. (1993). Gender differences in the acquisition of salary negotiation skills: The role of goals, self-efficacy, and perceived control. Journal of Applied Psychology, 78(5), 723-735.

Stuhlmacher, A. F., \& Walters, A. E. (1999). Gender differences in negotiation outcome: A meta-analysis. Personnel Psychology, 52(3), 653-677.

Thompson, L. (1990). Negotiation behavior and outcomes: Empirical evidence and theoretical issues. Psychological Bulletin, 108(3), 515-532.

Thompson, L. (2005). The mind and heart of the negotiator (3rd ed.). Upper Saddle River, N.J.: Prentice Hall.

Valley, K. L., White, S. B., Neale, M. A., \& Bazerman, M. H. (1992). Agents as information brokers: The effects of information disclosure on negotiated outcomes. Organizational Behavior and Human Decision Processes, 51(2), 220236.

Van Lange, P. A. M., \& Visser, K. (1999). Locomotion in social dilemmas: How people adapt to cooperative, tit-for-tat, and noncooperative partners. Journal of Personality and Social Psychology, 77(4), 762-773.

Wade, M. E. (2001). Women and salary negotiation: The costs of self-advocacy. Psychology of Women Quarterly, 25(1), 65-76. 
Wall, J. A. (1975). The effects of constituent trust and representative bargaining visibility on intergroup bargaining. Organizational Behavior and Human Decision Processes, 14(2), 244-256.

Wall, J. A., \& Adams, J. S. (1974). Some variables affecting a constituent's evaluations of and behavior toward a boundary role occupant. Organizational Behavior and Human Decision Processes, 11(3), 390-408.

Walters, A. E., Stuhlmacher, A. F., \& Meyer, L. L. (1998). Gender and negotiator competitiveness: A meta-analysis. Organizational Behavior and Human Decision Processes, 76(1), 1-29.

Walton, R. E., \& McKersie, R. (1965). A behavioral theory of labor negotiations. New York: McGraw Hill.

White, S. B., \& Neale, M. A. (1994). The role of negotiator aspirations and settlement expectancies in bargaining outcomes. Organizational Behavior and Human Decision Processes, 57(2), 303-318.

Wood, W., \& Karten, S. J. (1986). Sex differences in interaction style as a product of perceived sex differences in competence. Journal of Personality and Social Psychology, 50(2), 341-347.

Zanna, M. P., \& Pack, S. J. (1975). On the self-fulfilling nature of apparent sex differences in behavior. Journal of Experimental Social Psychology, 11(6), 583591. 
Appendix

Study 2

\section{Prenegotiation Questions}

1. What is your target price in this negotiation? In other words, what price per unit would you consider to be a good outcome for you in this negotiation?

2. Regardless of whether you want to make the first offer, if you had to put the first serious price number on the table, what amount would you offer?

\section{Post-negotiation Questions}

1. Did you reach agreement? (Check one: Yes/No) If yes, at what price per unit?

2. For how many minutes did you negotiate?

Study 3

Prenegotiation Question

1. What would be the total annual compensation in the best agreement that you hope to negotiate?

Post-negotiation Questions

1. Did you and your negotiating counterpart reach agreement? (Check one: Yes/No)

2. If you reached agreement, please describe below the total annual compensation package that [the candidate] will receive.

3. Did you negotiate with [the candidate] or [the mentor]? (Check one: I negotiated with [name of candidate]./I negotiated with [name of mentor].)

Study 4

Prenegotiation Survey Questions

1. What is the lowest wage per hour that you can accept? 
2. If you fail to reach agreement, how much will you be paid in addition to the show-up and early show-up fee (if applicable) for participating in today's exercise?

3. If you fail to reach agreement, how much will the student you represent in the negotiation be paid in addition to the show-up and early show-up fee (if applicable) for participating in today's exercise?*

4. If you reach agreement on a wage, how much will you be paid in addition to the show-up and early show-up fee (if applicable) for every dollar that you gain on the hourly wage above $\$ 30$ per hour?

5. If you reach agreement on a wage, how much will the student you represent be paid in addition to the show-up and early show-up fee (if applicable) for every dollar that you gain on the hourly wage above $\$ 30$ per hour? (other-representation condition only)*

*Questions distributed to sellers in other-representation condition only.

Post-negotiation Survey Questions

1. Did you reach agreement? (Check one: Yes/No) If yes, at what wage per hour?

2. For how many minutes did you negotiate? 
Author Note

Hannah Riley Bowles, John F. Kennedy School of Government, Harvard University; Linda Babcock, H. John Heinz III School of Public Policy and Management, Carnegie Mellon University; Kathleen L. McGinn, Graduate School of Business Administration, Harvard University.

This research is based on the first author's dissertation. It was supported by grants from the National Science Foundation SES-0213474, the Center for Public Leadership at the Kennedy School of Government, Harvard University, and the Harvard Business School. We are grateful for feedback and advice from Elaine Backman, Max Bazerman, Robin Ely, Michele Gelfand, Maureen Scully, Jim Sebenius, and Leigh Thompson. Correspondence concerning this manuscript should be addressed to Hannah Riley Bowles, Kennedy School of Government, 79 JFK Street, Cambridge, Massachusetts, 02138. Email: hannah_bowles@harvard.edu 


\section{Footnotes}

${ }^{1}$ In all four studies the distinction between male and female is based on indicators of biological sex rather than on sex-role identification (i.e., masculinity, femininity, androgyny) (Bem, 1974). We state hypotheses and discuss results in terms of "gender" effects as opposed to "sex" effects because the latter connotes "stable dispositions" rather than "fluctuating patterns" (Deaux \& LaFrance, 1998, p. 789). Embracing a gender-incontext perspective, we approach gender as a role that is enacted according to contextual cues (Deaux \& LaFrance, 1998; Deaux \& Major, 1987).

${ }^{2}$ In the interests of space and protection of the identity of the business school and because the control variables were included only to reduce the potential for omitted variable bias, we do not report a full set of descriptive statistics and correlations for these control variables.

${ }^{3}$ The cell count imbalance between male and female MBAs reduces the statistical power of our analysis. However, according to Rosenthal and Rosnow (1991), the harm associated with this level of imbalance is minimal. As such, we maintain confidence in the accuracy of our analysis. 
Table 1

Study 1: Descriptive Statistics for Salary (in thousands of dollars) by MBA Sex and Structural Ambiguity

\begin{tabular}{|c|c|c|c|c|}
\hline & & Overall & Female & Male \\
\hline \multirow[t]{3}{*}{ Total Sample } & $M$ & 98.14 & 94.09 & 100.03 \\
\hline & $S D$ & 19.49 & 15.08 & 20.99 \\
\hline & $n$ & 525 & 167 & 358 \\
\hline \multirow[t]{3}{*}{ Low Structural Ambiguity } & $M$ & 98.66 & 96.16 & 99.63 \\
\hline & $S D$ & 18.78 & 15.20 & 19.93 \\
\hline & $n$ & 360 & 100 & 260 \\
\hline \multirow[t]{3}{*}{ High Structural Ambiguity } & $M$ & 96.99 & 90.99 & 101.10 \\
\hline & $S D$ & 20.98 & 14.53 & 23.67 \\
\hline & $n$ & 165 & 67 & 98 \\
\hline
\end{tabular}


Table 2

Study 1: Regression Analysis of Log of Salary by MBA Sex and Structural Ambiguity (N $=525)$

\begin{tabular}{|c|c|c|c|c|}
\hline & Variables & $B^{\mathrm{a}}$ & $S E B$ & $\Delta R^{2}$ \\
\hline \multirow[t]{2}{*}{ Step 1} & Female MBA & $-.05^{* *}$ & .02 & $.29^{* * *}$ \\
\hline & Control Variables $^{\mathrm{b}}$ & & & \\
\hline \multirow[t]{4}{*}{ Step 2} & Female MBA & -.03 & .02 & $.01^{*}$ \\
\hline & Control Variables $^{\mathrm{b}}$ & & & \\
\hline & High Structural Ambiguity & $.06^{*}$ & .02 & \\
\hline & Female MBA $\times$ High Structural Ambiguity & $-.07^{*}$ & .03 & \\
\hline
\end{tabular}

${ }^{a}$ We do not report standardized beta coefficients, because dependent variable is in log form. ${ }^{b}$ Model included 31 control variables from five categories of salary predictors: job function (business development, consulting, finance, general management, marketing and venture capital/private equity as compared to other job functions), pre-MBA experience (years worked, pre-MBA salary, function experience, industry experience), job market activity (pre-MBA employer, offers received, job search activity), geographic location (U.S. city and Europe as compared to other location), and job preferences (debt payment, salary, equity/options, dual-career couple considerations, work/life balance, growth potential in company, expand experience, job content/level of responsibility, geography, people/company culture, obligation to previous employer, past experience at company, wanted company type, wanted function, wanted industry, other).

${ }^{*} p<.05 .{ }^{* *} p<.01 .{ }^{* * *} p<.001$. 


\section{Table 3}

Study 4: Analysis of Covariance of Agreement Wage by Sex of Seller, Representation Role and Structural Ambiguity

\begin{tabular}{lcccc}
\hline \multicolumn{1}{c}{ Source } & $d f$ & $M S$ & $F$ \\
\hline Structural Ambiguity & 1 & 37.03 & 2.54 \\
Sex of Seller & 1 & 27.50 & 1.89 \\
Representation Role & 1 & 6.57 & 0.45 \\
Structural Ambiguity $\times$ Sex of Seller & 1 & 39.64 & 2.72 \\
Structural Ambiguity $\times$ Representation Role & 1 & 6.10 & 0.42 \\
Sex of Seller $\times$ Representation Role & 1 & 17.48 & 1.20 \\
Structural Ambiguity $\times$ Sex of Seller $\times$ Representation Role & 1 & 110.07 & $7.54^{* *}$ \\
Error & 100 & & \\
\hline
\end{tabular}

Note: Model included a set of covariate indicators for work experience and educational background of buyer and seller.

${ }^{* *} p<.01$. 


\section{Figure Captions}

Figure 1. Study 2: Mean difference in female and male buyers' target prices, intended initial offers and agreement prices under low and high structural ambiguity (female $M-$ male $M$ ). Asterisks indicate significant mean sex difference within structural ambiguity condition.

${ }^{*} p \leq .05 .{ }^{* *} p<.01$.

Figure 2. Study 3: Mean compensation agreements by sex of seller and representation role. Asterisk indicates significant mean difference between self- and other-representation conditions.

${ }^{*} p<.05$. 


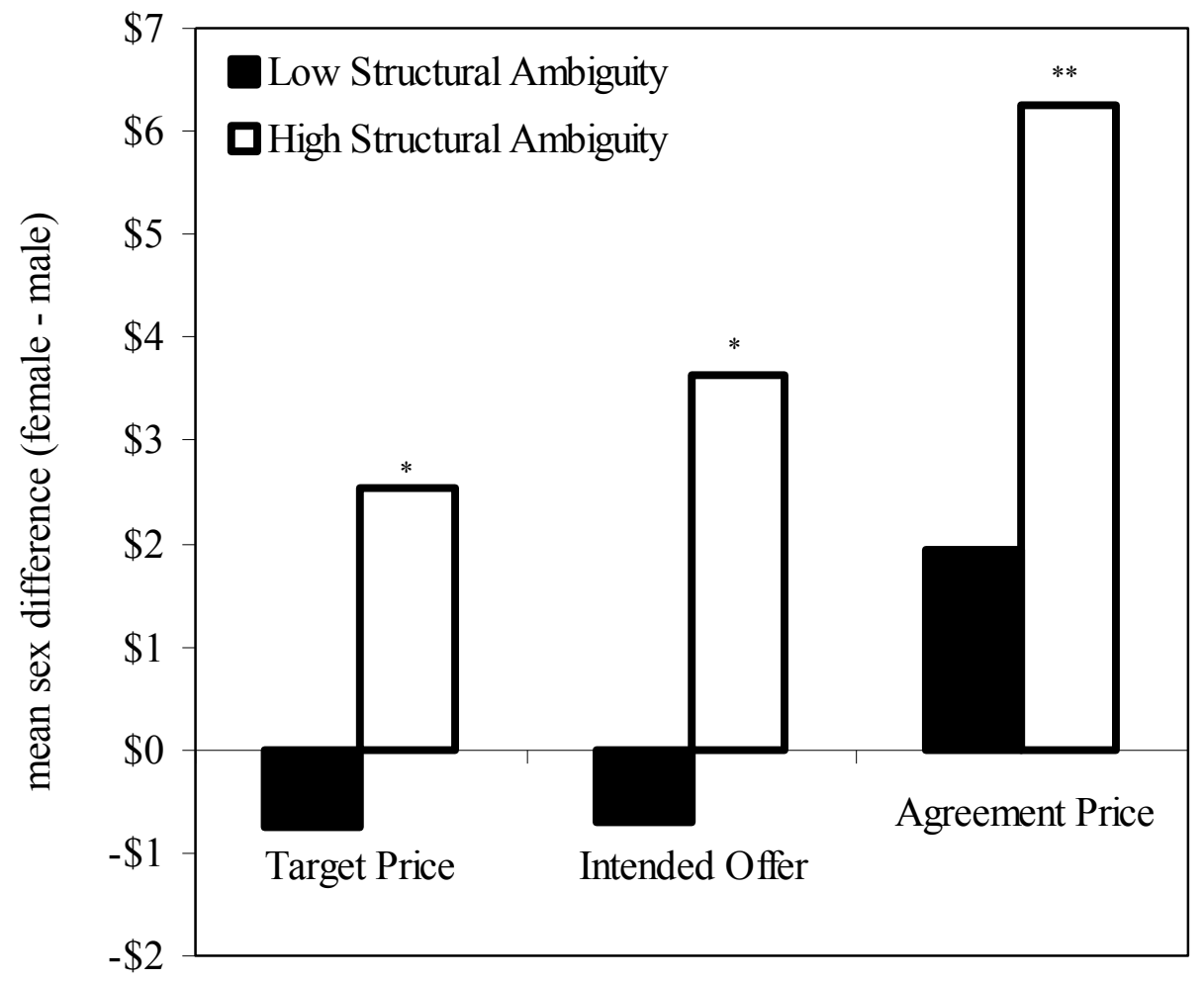




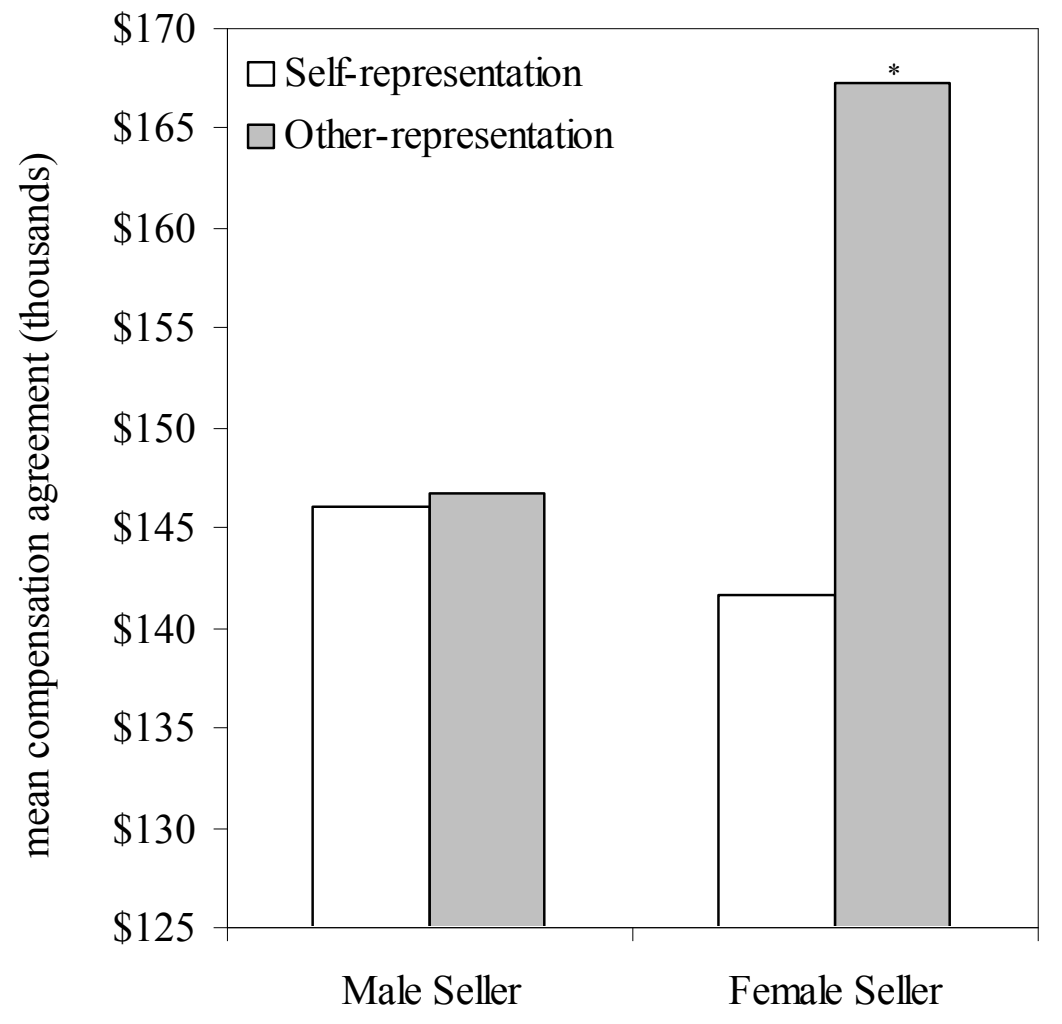

